\title{
Corneal densitometry changes in a patient with interface fluid syndrome after small incision lenticule extraction
}

\author{
Ke Zheng ${ }^{1 \dagger}$, Tian Han ${ }^{1 \dagger}$, Meiyan Li ${ }^{1}$, Yinan Han ${ }^{1}$, Ye Xu', Rupal Shah ${ }^{2}$ and Xingtao Zhou ${ }^{1 *}$ (D
}

\begin{abstract}
Background: To report a case of interface fluid syndrome (IFS) following small incision lenticule extraction (SMILE) evaluated with corneal densitometry and optical coherence tomography (OCT).

Case presentation: An 18-year-old man reported sudden vision loss 24 days after SMILE procedure. Intraocular pressure (IOP) was $36.3 \mathrm{mmHg}(\mathrm{OD})$ and $36.7 \mathrm{mmHg}(\mathrm{OS})$ by noncontact tonometry. Moderate corneal edema, interface fluid pocket and haze were observed by OCT and confirmed by corneal densitometry values. Discontinuation of steroids and addition of hypotensive medication were offered immediately. The symptoms were cured after the medication. Changes of corneal densitometry were consistent with the clinical course of IFS.

Conclusion: This case illustrates that it is crucial to be aware that a history of SMILE can also cause IFS. Both OCT and corneal densitometry can serve as auxiliary means to evaluate the clinical course of IFS, and appropriate IOP management is an effective approach.
\end{abstract}

Keywords: Small incision lenticule extraction (SMILE), Interface fluid syndrome (IFS), Corneal densitometry

\section{Background}

Interface fluid syndrome (IFS) is characterized by accumulation of aqueous humor in intrastromal space. Most of reports on IFS have been described following laser in situ keratomileusis (LASIK) surgery [1, 2]. IFS mostly results from increased intraocular pressure (IOP) triggered by postoperative steroid administration $[3,4]$. Rare causes of fluid accumulation include corneal endothelial cell decompensation [5-10]. IFS can be confused with diffuse lamellar keratitis (DLK), and misdiagnosis and inappropriate treatment can lead to irreversible visual field loss [4]. Moreover, IFS can occur a long time after LASIK, even 10 years afterwards [6, 7]. Thus, IFS should be kept in mind when prescribing steroids or performing other ocular surgery in patients with a history of LASIK.

Small incision lenticule extraction (SMILE) is a novel lamellar refractive surgery with a merely $2-\mathrm{mm}$ incision.

\footnotetext{
* Correspondence: doctzhouxingtao@163.com

${ }^{\dagger}$ Equal contributors

'Key Lab of Myopia, Ministry of Health, Department of Ophthalmology and Vision Science, Eye and ENT Hospital of Fudan University, No.19 Baoqing Road, Xuhui District, Shanghai, China

Full list of author information is available at the end of the article
}

Flap-related complications following LASIK surgery are avoided in SMILE surgery, which helps to gain popularity of SMILE. However, the space between corneal cap and stromal bed still exists in SMILE, indicating the possibility of interface complications [11]. We recently observed a case of IFS following SMILE surgery.

IFS can decrease corneal transparency, which can be revealed by the increase of corneal densitometry $[12,13]$. Thus, during the clinical course, anterior segment changes were observed using both optical coherence tomography (OCT) and an automated Scheimpflug densitometry program.

\section{Case presentation}

An 18-year-old man underwent bilateral routine SMILE procedure with preoperative refraction of $-6.00 /-2.25 \times 175$ (OD) and $-6.50 /-1.75 \times 180$ (OS), and corrected distance visual acuity (CDVA) was 20/16 in both eyes. After the surgery, topical antibiotics (tobrex) and a non-preservative tear supplement were used. Topical steroids (fluorometholone $0.1 \%$ ) were used initially eight times daily and tapered every three days. The patient ran out of fluorometholone $0.1 \%$ at 14 days postoperatively and local ophthalmologist 
prescribed him tobramycin-dexamethasone (tobradex) eyedrops three times daily for 4 days at 20 days postoperatively.

Then at 24 days postoperatively, the patient sought treatment for sudden vision loss. Uncorrected distance visual acuity (UDVA) was 20/80 in both eyes. Refraction was $-3.75 /-1.25 \times 180(\mathrm{OD})$ and $-3.75 /-0.50 \times 180$ (OS), and CDVA was $20 / 25$ in both eyes. IOP was $36.3 \mathrm{mmHg}$ (OD) and $36.7 \mathrm{mmHg}$ (OS) by noncontact tonometry (NCT; Canon TX-20, Canon Corp., Japan). Slitlamp examination revealed interface haze and corneal edema, and fourier-domain optical coherence tomography (FDOCT; RTVue, Optovue, Corp., USA) showed interface fluid accumulation in the cap-bed interface of both eyes (Fig. 1-a). Tobramycin-dexamethasone was stopped, an intravenous mannitol drip, carteolol hydrochloride eyedrops twice daily, pranoprofen eyedrops four times daily and $12.5 \mathrm{mg}$ methazolamide twice daily were immediately administered. Eight hours after the treatment, IOP was $14.7 \mathrm{mmHg}(\mathrm{OD})$ and $17.2 \mathrm{mmHg}(\mathrm{OS})$. The next day, UDVA recovered to $20 / 25$ in both eyes. Refraction was $-2.00 /-0.50 \times 175(\mathrm{OD})$ and $-2.00 /-0.50 \times 10$ (OS), and CDVA was $20 / 20$ in both eyes. IOP was $16.1 \mathrm{mmHg}$ (OD) and $16.7 \mathrm{mmHg}$ (OS). Corneal endothelial densities measured by specular microscopy (Topcon SP2000P, Topcon Corp., Japan) were 3800 cells $/ \mathrm{mm}^{2}$ (OD) and 3232 cells $/ \mathrm{mm}^{2}$ (OS). Interface haze and cornea edema were relieved under slitlamp examination. OCT showed that interface fluid accumulation in the cap-bed interface of both eyes was also absorbed (Fig. 1-b). The intravenous mannitol drip and methazolamide were discontinued, but pranoprofen and carteolol hydrochloride eyedrops were continued.

Two days later, UDVA was $20 / 20$ in both eyes, with refraction of $-0.50 /-0.50 \times 180$ (OD) \& $-0.50 /-0.25 \times 15$
(OS), and CDVA of 20/16 in both eyes. IOP was $11.2 \mathrm{mmHg}(\mathrm{OD})$ and $11.7 \mathrm{mmHg}(\mathrm{OS})$. The cornea was clear under slitlamp examination. OCT showed merely mild microdistortions in Bowman's layer (Fig. 1-c). The carteolol hydrochloride eyedrops was discontinued, but pranoprofen eyedrops was continued. At 33 days postoperatively, his visual acuity and IOP remained stable in both eyes. Changes of corneal densitometry and central corneal thickness values using rotating Scheimpflug camera imaging (Pentacam HR 70900, OCULUS Corp., Germany) were shown in Table 1.

\section{Discussion and conclusions}

Since Lyle and Jin [2] reported the first case of IFS after LASIK in 1999, the awareness of IFS has been promoted by increasing reports $[4,6,7,14]$. As one of the lamellar refractive surgeries, SMILE generates space between corneal cap and stromal bed as LASIK, interface complications such as IFS can happen in SMILE [11]. This case is the first IFS case after SMILE procedure for the surgeon (XTZ) (incidence: nearly 1: 10000).

In this case, moderate corneal edema, interface fluid pocket and haze were observed, corresponding to stage 2 IFS according to Dawson's grading system [1]. Dawson et al. [1] classified IFS into stages ranging from 1 to 3 based on the degree of fluid retention in the flap interface. IFS stage 2 sometimes can be confused with the slit-lamp appearance of DLK stage 1 or 2 , but the treatments of the two diseases are totally distinct from each other. Misdiagnosis can cause optic nerve damage, irreversible visual field loss and central visual acuity decrease [4]. In addition, NCT has been shown to be dependent on central corneal thickness (CCT). In this case, NCT was underestimated due to decreased CCT and presence of interface fluid. It would be more

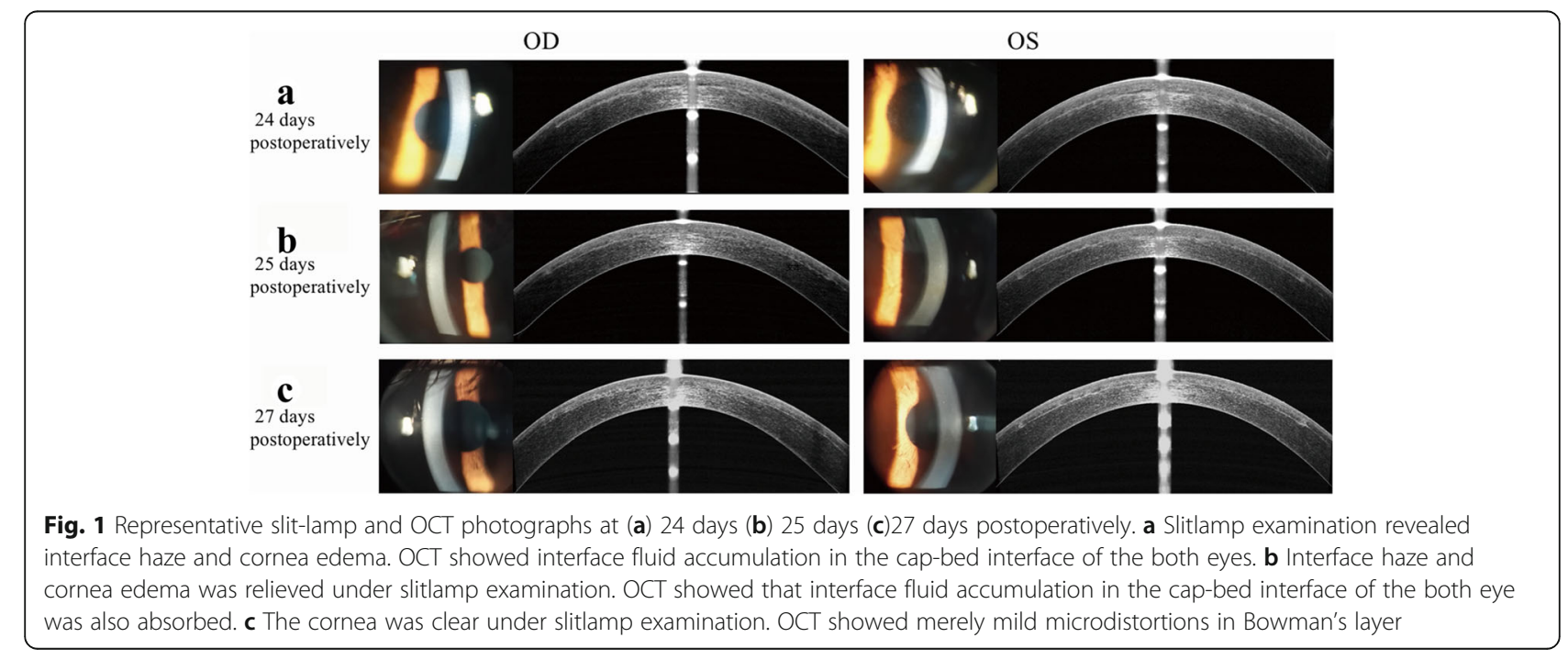


Table 1 Corneal densitometry and CCT Changes of a patient with IFS

\begin{tabular}{|c|c|c|c|c|c|c|}
\hline \multirow[t]{2}{*}{ Time } & \multicolumn{3}{|l|}{ OD } & \multicolumn{3}{|l|}{ OS } \\
\hline & $\begin{array}{l}\text { Anterior layer in } \\
\text { total diameter }\end{array}$ & Central point (maximum) & $\mathrm{CCT}(\mu \mathrm{m})$ & $\begin{array}{l}\text { Anterior layer in } \\
\text { total diameter }\end{array}$ & Central point (maximum) & $\mathrm{CCT}(\mu \mathrm{m})$ \\
\hline Pre-operation & 19.2 & 28.2 & 523 & 20.3 & 25.9 & 520 \\
\hline $\begin{array}{l}24 \text { days postoperatively } \\
\text { (IFS was detected) }\end{array}$ & 30.8 & 32.5 & 491 & 31.3 & 45.4 & 490 \\
\hline 25 days postoperatively & 23.9 & 30.6 & 440 & 23.0 & 31.8 & 434 \\
\hline 26 days postoperatively & 23.6 & 30.2 & 421 & 22.9 & 29.4 & 429 \\
\hline 27 days postoperatively & 20.7 & 26.7 & 410 & 21.9 & 27.8 & 409 \\
\hline 33 days postoperatively & 21.2 & 26.7 & 406 & 21.0 & 31.4 & 401 \\
\hline
\end{tabular}

IFS Interface fluid syndrome

CCT Central corneal thickness

accurate to measure IOP with other types of tonometry, especially dynamic contour tonometry, which may be less affected by CCT. Clinically, inaccurately low measurements of central IOP owing to cushioning of the fluid pocket can also confuse the diagnosis [15].

IFS was caused by elevated IOP in this case since the patient inappropriately applied tobramycin-dexamethasone three times for 4 days. Use of steroids is the most common reason of IFS [3, 4]. Other causes of IFS after LASIK are related to transient or permanent corneal endothelial cell decompensation in eyes with anterior uveitis [10], Fuchs endothelial dystrophy [8], traumatic hyphema [14] and eyes that have undergone certain procedures such as cataract surgery [7], vitreoretinal surgery [6], Descemet stripping automated endothelial keratoplasty (DSAEK) [5] or trabeculectomy [9]. These risk factors for interface fluid syndrome after LASIK should also be noted in postSMILE eyes.

The refraction of the patient in this case changed from more than $-3.00 \mathrm{D}$ to $-0.75 \mathrm{D}$ during the clinical course, and the myopic shift influenced by IFS also indicated the condition of IFS.

Another interesting aspect of our case is the use of automated Scheimpflug densitometry program. Studies of corneal densitometry have attracted increasing interest over the past few years $[12,13]$. Considering that IFS mainly affected the transparency of the anterior corneal layer, we show in Table 1 the densitometry of the total diameter of this layer and maximum central point. As shown in Table 1, the corneal densitometry increased at 24 days postoperatively. Corneal densitometry increases when edema, haze or inflammation occurs $[12,13]$. According to our research, corneal densitometry declined to the baseline within a week after SMILE (J Refract Surg, 2017). Thus, in this case, the increase of corneal densitometry was mainly related to IFS. Moreover, the changes of corneal densitometry were consistent with the clinical course of IFS. Along with the recovery of IFS, corneal densitometry declined distinctly. Therefore, the corneal densitometry can be useful for evaluating and grading the condition of IFS quantitatively and objectively.

This case illustrates that it is crucial to be aware that a history of SMILE can also cause IFS. Both OCT and corneal densitometry can serve as auxiliary means to evaluate the clinical course of IFS, and appropriate IOP management is an effective approach.

\section{Abbreviations}

ANOVA: Analysis of variance; CDVA: Corrected distance visual acuity; D: Diopters; HOAs: Higher-order aberrations; IQR: Interquartile range; LASIK: Laser in situ keratomileusis; PRK: Photorefractive keratectomy; QIRC: Quality of Life Impact of Refractive Correction; RMS: Root mean square; SE: Spherical equivalent; SMILE: Small incision lenticule extraction;

SPSS: Statistical Package for Social Sciences; UDVA: Uncorrected distance visual acuity

\section{Acknowledgements}

None.

\section{Funding}

Supported in part by the National Natural Science Foundation of China for Young Scholars (Grant No. 81500753), the National Natural Science Foundation of China for Young Scholars (Grant No. 81600762), and the National Natural Science Foundation of China (Grant No. 81570879) in collection of data.

\section{Availability of data and materials}

All data supporting our findings will be shared upon request, although the majority is contained within the manuscript.

\section{Authors' contributions}

Literature screening was performed by $\mathrm{KZ}$ and $\mathrm{TH}$. All authors collected and interpreted the data. KZ and TH drafted the manuscript. MYL, YNH, YX, RS and XTZ revised and reviewed of the manuscript. All authors gave final approval of the version to be published.

Competing interests

The authors declare that they have no competing interests.

\section{Consent for publication}

Written informed consent was obtained from the patient for publication of this case report and any accompanying images.

Ethics approval and consent to participate Not applicable. 


\section{Publisher's Note}

Springer Nature remains neutral with regard to jurisdictional claims in published maps and institutional affiliations.

\section{Author details}

${ }^{1}$ Key Lab of Myopia, Ministry of Health, Department of Ophthalmology and Vision Science, Eye and ENT Hospital of Fudan University, No.19 Baoqing Road, Xuhui District, Shanghai, China. ${ }^{2}$ New Vision Laser Centers, Vadodara, Gujarat, India.

Received: 21 November 2016 Accepted: 20 March 2017

Published online: 29 March 2017

\section{References}

1. Dawson DG, Schmack I, Holley GP, Waring 3rd GO, Grossniklaus HE, Edelhauser HF. Interface fluid syndrome in human eye bank corneas after LASIK: causes and pathogenesis. Ophthalmology. 2007;114(10):1848-59.

2. Lyle WA, Jin GJ. Interface fluid associated with diffuse lamellar keratitis and epithelial ingrowth after laser in situ keratomileusis. J Cataract Refract Surg. 1999:25(7):1009-12.

3. Moya Calleja T, Iribarne Ferrer Y, Sanz Jorge A, Sedo FS. Steroid-induced interface fluid syndrome after LASIK. J Refract Surg. 2009;25(2):235-9.

4. Randleman JB, Lesser GR. Glaucomatous damage from pressure-induced stromal keratopathy after LASIK. J Refract Surg. 2012;28(6):378-9.

5. Hurmeric V, Wang J, Kymionis GD, Yoo SH. Persistent lamellar interface fluid with clear cornea after Descemet stripping automated endothelial keratoplasty. Cornea. 2011;30(12):1485-7.

6. Han SB, Woo SJ, Hyon JY. Delayed-onset interface fluid syndrome after laser in situ keratomileusis secondary to combined cataract and vitreoretinal surgery. J Cataract Refract Surg. 2012;38(3):548-50.

7. Ortega-Usobiaga J, Martin-Reyes C, Llovet-Osuna F, Damas-Mateache B, Baviera-Sabater J. Interface fluid syndrome in routine cataract surgery 10 years after laser in situ keratomileusis. Cornea. 2012;31(6):706-7.

8. Dastjerdi $\mathrm{MH}$, Sugar A. Corneal decompensation after laser in situ keratomileusis in fuchs' endothelial dystrophy. Cornea. 2003;22(4):379-81.

9. Kang SJ, Dawson DG, Hopp LM, Schmack I, Grossniklaus HE, Edelhauser HF. Interface fluid syndrome in laser in situ keratomileusis after complicated trabeculectomy. J Cataract Refract Surg. 2006;32(9):1560-2.

10. McLeod SD, Mather R, Hwang DG, Margolis TP. Uveitis-associated flap edema and lamellar interface fluid collection after LASIK. Am J Ophthalmol. 2005;139(6):1137-9.

11. Bansal AK, Murthy SI, Maaz SM, Sachdev MS. Shifting "Ectasia": Interface Fluid Collection After Small Incision Lenticule Extraction (SMILE). J Refract Surg. 2016;32(11):773-5.

12. Savini G, Huang J, Lombardo M, Serrao S, Schiano-Lomoriello D, Venanzio S, Ducoli P. Objective Monitoring of Corneal Backward Light Scattering After Femtosecond Laser-assisted LASIK. J Refract Surg. 2016:32(1):20-5.

13. Greenstein SA, Fry KL, Bhatt J, Hersh PS. Natural history of corneal haze after collagen crosslinking for keratoconus and corneal ectasia: Scheimpflug and biomicroscopic analysis. J Cataract Refract Surg. 2010;36(12):2105-14.

14. Liu X, Ling S, Gao X, Xu C, Wang F. Pressure-induced stromal keratopathy as a result of ocular trauma after laser in situ keratomileusis. JAMA Ophthalmol. 2013;131(8):1070-2.

15. Najman-Vainer J, Smith RJ, Maloney RK. Interface fluid after LASIK: misleading tonometry can lead to end-stage glaucoma. J Cataract Refract Surg. 2000;26(4):471-2

\section{Submit your next manuscript to BioMed Central and we will help you at every step:}

- We accept pre-submission inquiries

- Our selector tool helps you to find the most relevant journal

- We provide round the clock customer support

- Convenient online submission

- Thorough peer review

- Inclusion in PubMed and all major indexing services

- Maximum visibility for your research

Submit your manuscript at www.biomedcentral.com/submit 